\title{
Severe Ulceration of the Stomach after Endoscopic Injection Sclerotherapy
}

Endoscopic injection sclerotherapy (EIS) is a major therapeutic modality for the treatment of patients with bleeding from ruptured esophageal varices [1]. In addition, it has been demonstrated that prophylactic sclerotherapy in cirrhotic patients with known varices can reduce the rate of subsequent bleeding and improve survival [2]. The complications of endoscopic sclerotherapy include, for example, esophageal ulceration and esophageal perforation [3]. However, few reports have focused on the development of gastric ulcers following sclerotherapy [4].

A 45-year-old man was admitted to our hospital with liver cirrhosis due to hepatitis virus $\mathrm{B}$ and esophageal varices. His varices were classified as $\mathrm{LiF}_{2} \mathrm{CbRC}(+) \mathrm{Lg}-$ $\mathrm{cf}(+)$ according to the general rules for study of portal hypertension [5]. About 5 months prior to admission, he had undergone three uneventful sessions of sclerotherapy for risk-associated esophageal varices. At 3 days after admission, he underwent EIS; a total of $10 \mathrm{ml}$ of $5 \%$ ethanolamine oleate was injected into several large varices at different sites under radiographic guidance (Figure $\mathbf{1}$ ). The patient had a moderate degree of upper epigastric discomfort following the procedure. The abdominal pain increased and the patient vomited blood on the morning after the procedure. A subsequent endoscopy examination revealed a large gastric ulcer in the lesser curvature of the gastric body (Figure 2 ). A computed tomography examination also showed a low-density area in the lesser curvature of the gastric body. The giant gastric ulcer, which responded to conservative therapy, appeared to be healing at 1 month after the sclerotherapy.

In view of its location, the giant gastric ulcer may have formed because of ischemia as a result of arterial obstruction by the sclerosant. Only one previous report has focused on the formation of gastric ulcers following sclerotherapy. Asano et al. [4] reported that a gastric arterial branch was detected in a portion of an ulcer by

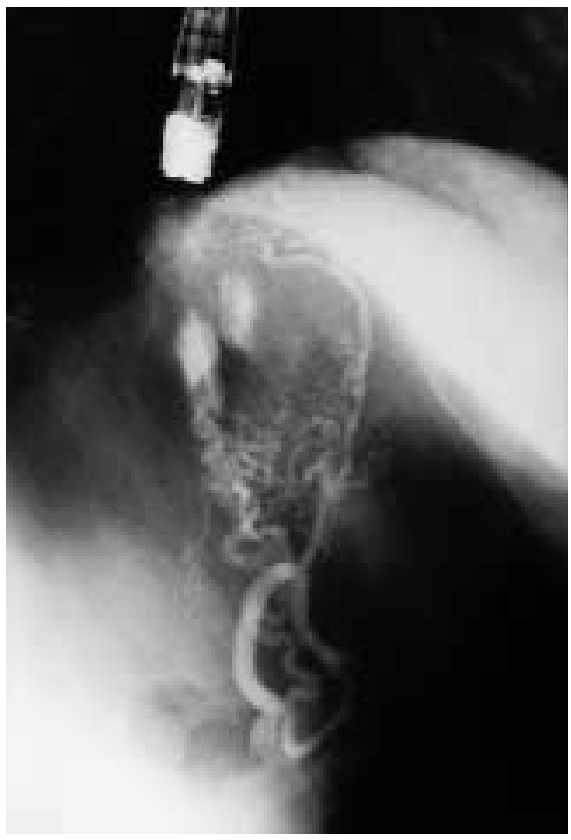

Figure 1 Endoscopic varicealography performed during endoscopic injection sclerotherapy (EIS) shows the left gastric vein through the fundic plexus; however the left gastric artery branch is not visible.

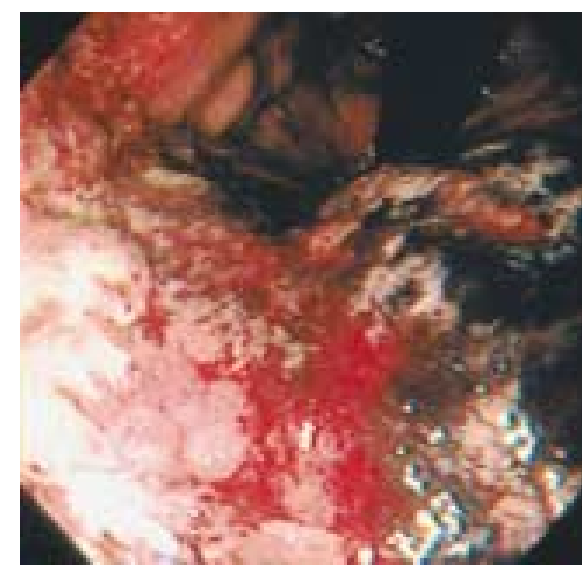

Figure 2 Endoscopic image showing a giant gastric ulcer on the lesser curvature of the gastric body, 1 day after the EIS.

means of varicealography; however we did not observe any gastric arterial branches in the present case. Giant gastric ulcer is a very rare but serious complication of sclerotherapy.
M. Inamori, J. Togawa, H. Kawamura, Y. Abe, H. Naitoh, H. Nagase,

A. Nakajima, T. Saito, S. Tominaga, N. Ueno, K. Tanaka, H. Sekihara

Third Department of Internal Medicine, Yokohama City University School of Medicine, Yokohama, Japan.

\section{References}

${ }^{1}$ Allison JG. The role of injection sclerotherapy in the emergency and definitive management of bleeding esophageal varices. J Am Med Assoc 1983; 249: 1484- 1487

2 Paquet KJ. Prophylactic endoscopic sclerosing treatment of the esophageal wall in varices - a prospective controlled randomized trial. Endoscopy 1982; 14: 4-5

${ }^{3}$ Bacon BR, Camara DS, Duffy MC. Severe ulceration and delayed perforation of the esophagus after endoscopic variceal sclerotherapy. Gastrointest Endosc 1987; 33: 311 - 315

${ }^{4}$ Asano A, Kokubu S, Murakami M et al. A case of autoimmune hepatitis with giant ulcer of the stomach after EIS for recurrent esophageal varices; visualization of left gastric artery in endoscopic varicealography. Gastroenterol Endosc 1997; 39: $2397-2403$

${ }^{5}$ Idezuki Y. General rules for recording endoscopic findings of esophagogastric varices (1991). Japanese Society for Portal Hypertension. World J Surg 1995; 19: $420-423$

\section{Corresponding Author}

\section{Inamori, M.D.}

Third Department of Internal Medicine Yokohama City University

\section{3-9 Fukuura}

Kanazawa-ku

Yokohama 236-0004

Japan

Fax: $\quad+81-45-7843546$

E-mail: inamorim@med.yokohamacu.ac.jp 